\title{
RESEARCH
}

Open Access

\section{Addition of MoodGYM to physical treatments for chronic low back pain: A randomized controlled trial}

\author{
M. John Petrozzi ${ }^{1 *}$ (D), Andrew Leaver ${ }^{1}$, Paulo H. Ferreira', Sidney M. Rubinstein², Mairwen K. Jones ${ }^{3}$ \\ and Martin G. Mackey ${ }^{1}$
}

\begin{abstract}
Background: Low back pain (LBP) is prevalent, costly and disabling. A biopsychosocial treatment approach involving physical and cognitive behavioural therapy (CBT) is recommended for those with chronic LBP. It is not known if online psychological coaching tools might have a role in the secondary prevention of LBP related disability. To assess the effectiveness of an internet-delivered psychological program (MoodGYM) in addition to standard physical treatment in patients with chronic non-specific LBP at medium risk of ongoing disability.
\end{abstract}

Methods: A multisite randomized controlled trial was conducted with 108 participants (aged mean $50.4 \pm 13.6$ years) with chronic LBP attending one of six private physiotherapy or chiropractic clinics. Disability (Roland Morris Disability Questionnaire) and self-efficacy (Patient Self-Efficacy Questionnaire), were assessed at baseline, post-treatment (8-weeks) with follow-up at six-and twelve-months. Participants were randomized into either the intervention group, MoodGYM plus physical treatments, or the control group which received physical treatments alone.

Results: No statistically significant between group differences were observed for either disability at posttreatment (Effect size (standardised mean difference) 95\% Cl) RMD - $0.06(-0.45,0.31)$, 6-months RMD 0.01 ($0.38,0.39)$ and 12 -months $-0.20(-0.62,0.17)$ or self-efficacy at post-treatment PSEQ $0.06(-0.31,0.45)$, 6 -months $0.02(-0.36,0.41)$ and 12-months $0.21(-0.16,0.63)$.

Conclusion: There was no additional benefit of an internet-delivered CBT program (MoodGYM) to physical treatments in those with chronic non-specific LBP at medium risk of ongoing disability measured at posttreatment, or at 6 and 12 months.

Trial registration: This trial was prospectively registered with Australian New Zealand Clinical Trials Registry Number (ACTRN) 12615000269538.

Keywords: Chronic non-specific LBP, Disability, Self-efficacy, MoodGYM, Secondary psychosocial prevention, Chiropractic

\footnotetext{
* Correspondence: mpet9893@uni.sydney.edu.au

${ }^{1}$ Discipline of Physiotherapy, Faculty of Health Sciences, The University of

Sydney, Sydney, Australia

Full list of author information is available at the end of the article
}

(c) The Author(s). 2019 Open Access This article is distributed under the terms of the Creative Commons Attribution 4.0 International License (http://creativecommons.org/licenses/by/4.0/), which permits unrestricted use, distribution, and reproduction in any medium, provided you give appropriate credit to the original author(s) and the source, provide a link to the Creative Commons license, and indicate if changes were made. The Creative Commons Public Domain Dedication waiver (http://creativecommons.org/publicdomain/zero/1.0/) applies to the data made available in this article, unless otherwise stated. 


\section{Background}

Chronic non-specific low back pain (LBP) is a complex biopsychosocial condition. Evidence suggests underlying psychosocial factors, including poor self-efficacy, depression and pain catastrophising, are possible factors for poor response to physical treatment [1]. A Cochrane review found more effectiveness of biopsychosocial treatments compared to physical treatments for LBP, disability and work status in those with chronic nonspecific LBP [2].

Non-specific LBP is the most common form of low back pain, and has an undetermined pathoanatomical cause [3]. Best practice management includes advice about staying active, reassurance that activity will not worsen the problem, exercise [4-7], and a short-course of physical treatments such as manual therapy including spinal manipulative therapy, soft tissue and joint mobilisation [8-12].

Individuals at medium-risk of ongoing disability may have little to no psychosocial issues, compared to those at high-risk, it is argued that some at medium-risk who do not respond to physical treatments may continue to experience ongoing disability that may be due to some psychosocial factors not detected by the STarT Back screening tool (SBST). It is argued therefore that adding a biopsychosocial intervention, such as cognitive behavioural therapy (CBT) to physical treatments, as a secondary prevention measure, for those at medium-risk of ongoing disability may improve outcomes by addressing both physical, and any concurrent psychosocial dimensions of their condition [13]. This combined intervention is endorsed by clinical practice guidelines [10,12].

CBT interventions improve disability and back pain, as well as self-efficacy and associated depression and anxiety [2]. According to Bandura, the concept of selfefficacy is likened to one's belief in their ability to complete a task despite the presence of a pain [14]. CBT is usually delivered face-to-face, however, can also be delivered over the internet. Internet-delivered CBT, may be advantageous as it can be provided at no cost and accessed anytime with potentially less societal stigma [15-17]. Internet-delivered CBT has provided immediate and sustained improvements in primary depressive symptoms at three and six months follow-ups [15]. A 2016 systematic review found internet-delivered CBT had small effects on disability, and pain intensity, the baseline levels of psychological distress in these studies was mild to moderate [18].

MoodGYM is a primary and secondary prevention internet-delivered program preventing and managing depressive symptoms in people with troubling but not incapacitating symptoms [19]. It is widely accessible and no cost. MoodGYM consists of five self-help modules (Table 1), exploring thoughts, feelings, stressors and
Table 1 MoodGYM modules and content

\begin{tabular}{ll}
\hline Module & Module content \\
\hline Module 1 & Feelings: Why you feel the way you do \\
Module 2 & Thoughts: Changing the way we think \\
Module 3 & Unwarping: Changing warped thoughts \\
Module 4 & De-stressing: Knowing what makes you upset \\
Module 5 & Relationships: Relationships and how they work out \\
\hline
\end{tabular}

relationships that may contribute to psychosocial distress. MoodGYM has shown small sustained improvements on self-esteem (a similar construct to selfefficacy), effect size 0.16 [20]. MoodGYM has been examined in populations with a chronic condition to manage psychosocial symptoms [21, 22], though has not previously been in back pain populations. MoodGYM was selected in preference to other programs as it has met evidence standards for effectiveness [23] and standards of evidence for public dissemination [24]. This program might be of benefit in people with chronic LBP. Furthermore, other programs available at the time were not as well researched, nor were they as popularly utilised as MoodGYM was with over 1 million registered users [25].

Therefore, the aim and hypothesis of this study was to determine whether combined MoodGYM and physical treatments was more effective than physical treatments alone for reducing disability and increasing self-efficacy in people at medium-risk of ongoing chronic nonspecific LBP.

\section{Methods \\ Design}

This study was a single-blinded, multicentred, randomized controlled trial conducted across six chiropractic and physiotherapy clinics in metropolitan New South Wales and Victoria, Australia. The Consolidated Standards of Reporting Trial (CONSORT) guidelines were followed for reporting this randomized trial [26]. The trial protocol was registered prospectively with the Australian New Zealand Clinical Trials Registry Number (ACTRN) 12615000269538 and published [27]. Furthermore, the trial was approved by The University of Sydney Human Research Ethics Committee (protocol number 2014/997). All participants provided written informed consent prior to entering the trial. Recruitment commenced on March 30, 2015 and ended June 2017.

\section{Participants}

Volunteers with chronic LBP were recruited through advertisements in participating practices including, medical and allied health centres in metropolitan Sydney and Geelong, as well on the university trial recruitment website and featured editorials in local newspapers. Respondents 
were informed about the trial and provided with a Participant Information Statement (PIS) and screened for inclusion by an independent research assistant. Those satisfying the inclusion criteria, and subsequently provided written informed consent were included.

Inclusion criteria: participants over 18 years of age were included if they had non-specific LBP greater than three months duration but had not received manual therapy in the previous three months. The validated risk stratification STarT Back Screening Tool was used to stratify participants at medium risk of ongoing disability [28].

Exclusion criteria: participants were excluded if diagnosed with any of the following: serious spinal pathology (fracture, malignancy, infection, inflammatory disorders, canal stenosis or cauda equina syndrome, spinal cord injury), spinal nerve compromise (determined by the presence of two or more corresponding neurological signs such as dermatomal paresthesia, myotomal weakness, diminished or absent deep tendon reflexes), had undergone spinal surgery in the previous 12 months, were pregnant, had a compensation claim related to their back condition, were unable to independently complete English language questionnaires or unable to independently use a computer.

\section{Interventions}

Participants were randomised into one of two treatment groups: Control Group (1) which received standard care (physical treatments) only, or the Intervention Group (2) which received a combination of standard care (physical treatments) and access to a self-administered program of MoodGYM. Participants were instructed to not reveal their group allocation with their treating practitioner. Protocol was published prospectively [27].

Physical treatments were provided by a registered chiropractor or physiotherapist with more than 5 years' manual therapy experience. The treatments were provided at no cost to the participants and participants were not precluded from seeking care outside of the trial. The therapists were inducted into the trial and given a regimen of standard physical treatments that were selected pragmatically according to therapist and participant preference. Physical treatments included manual therapy in combination with other modalities such as advice, education and exercise [8, 11, 29]. Manual therapy included spinal manipulation or mobilization and/or soft tissue massage. Advice and education consisted of reassurance and advice about symptom management and encouragement to remain active. Practitioners were instructed to provide key messages that low back pain is mostly benign and self-limiting, principles of activity pacing, along with instruction on safe manual handling, and general postural advice. Participants were also encouraged to remain physically active and avoid excessive bedrest. Exercise therapy included a specific exercise or general conditioning regimen. Specific therapeutic exercise focused on correction of strength, mobility of motor control impairments or general conditioning exercises were prescribed at the discretion of the treating practitioner. Each participant received up to 12 sessions of physical treatment. The frequency and total number of treatments was determined by the clinical judgement and patient response. Treatment was discontinued if the participant experienced either significant improvements in function and/or pain indicating recovery, or a serious or severe adverse response to treatment. The number and type of treatments delivered was recorded by the treating practitioner. Compliance to suggested treatment plan and prescribed exercises was verbally discussed and noted at the time of treatment.

Intervention Group participants received the same physical treatments as the Control Group with the addition of access to the MoodGYM program [30]. We used MoodGYM modules as a secondary prevention tool for teaching people to better respond to troubling emotions or psychological distress. The program presented a combination of written information, real-life examples and quizzes, delivered within the principles of a CBT framework. Module 1 provided information about the felt experience of troubling emotions; module 2 and 3 provided CBT-based information and behavioural exercises that taught participants how to adapt healthier thoughts and behaviours in daily life; module 4 provided information about psychological distress and provided behavioural coping strategies; module 5 presented interpersonal problem solving strategies that could be used to prevent psychological distress in personal relationships. Participants were provided with a MoodGYM user manual briefly outlining the website address and how to create a personal login to the program [31]. No further assistance was provided above and beyond what is already available to public internet users. Participants were instructed to work through one module per week whilst concurrently undertaking their physical treatments. No face-to-face counselling was provided outside of the interaction received with MoodGYM. An online log which could track participant use of MoodGYM was not available to the researchers. However, each participant received a weekly telephone call from an independent research assistant to assess and encourage adherence to the online program. Provision was made for any participants who reported severe distress at time of weekly telephone call as a result of using MoodGYM to be referred to a clinical psychologist.

\section{Randomisation and blinding}

The randomisation process was conducted by an independent research assistant, before the trial commenced. 
This research assistant was not involved in participant recruitment, treatment delivery, data collection or analysis. A computer-generated random number sequence of 108 treatment assignments resulted in an equal number of 54 assignments between the two groups. Block randomisation was not used. These group allocations (Control or Intervention) were individually sealed in consecutively numbered opaque envelopes by the research assistant. Immediately after participant enrolment, another independent research assistant opened the next available envelope to reveal the participants treatment group allocation. Once allocated, the participant was not able to change groups. The group allocation was only known by the research assistant and the participant. Participants were instructed not to divulge group allocation to their treating practitioner. Furthermore, participants were not fully informed as to the nature of the intervention CBT program at time of recruitment. Namely, participants in the Control Group were not able to purposefully access MoodGYM during the trial as it was not specifically mentioned in the study advertisement, participant information statement or discussed by the treating practitioner or their staff. As the treating practitioner was blinded to group allocation, participants were instructed not to discuss MoodGym with them.

\section{Data collection and outcome measures}

Baseline data collection included demographic and clinical characteristics: gender, age, work status, functional impairment, treatment history and medical history, selfefficacy, disability, pain intensity, pain catastrophizing, stress anxiety and depression and work ability. All outcomes scores were collected again at post-treatment $(8$ weeks), and at 6- and 12- month follow-up. Participants entered responses directly into an online survey collection database (Survey Monkey@).

\section{Primary outcomes}

Primary outcomes were self-efficacy and low back painrelated disability. Self-efficacy is a persons' belief and confidence that a physical task can be performed despite sensations of pain [32]. The Pain Self Efficacy Questionnaire (PSEQ) measured self-efficacy, range 0 to 60 , where a higher score reflected higher self-efficacy [33].

The Roland Morris Disability Questionnaire (RMD) [34] measured disability, range 0 to 24 , where a higher score reflects higher disability [34].

\section{Secondary outcomes}

Secondary outcome were Pain Catastrophizing Scale (PCS) [35, 36], Patient Specific Functional Scale (PSFS) [37], Depression Anxiety and Stress Scale (DASS21) [38], Pain Numerical Rating Scale (PNRS) [39] and
Work Ability, using the single item Work Ability Index (WAI) score [31].

All instruments were validated outcomes whose psychometric properties have been outlined previously [27].

\section{Adverse events outcomes}

Adverse events were monitored according to the revised and extended 2003 CONSORT statement for reporting clinical trial data [40]. A serious adverse event from physical treatment was defined as any untoward occurrence resulting in hospitalization, life threatening injury that results in persistent significant disability or incapacity or death [41]. An enquiry for any minor, moderate or severe physical treatment adverse event [42] was made by the practitioner at each treatment session investigating: 1) a new related complaint which was not present at baseline or previous visit, or 2) a worsening of the presenting complaint [43]. Adverse events from physical treatments were measured at each treatment by two questions which the participant self-scored on a 10point scale from 1(Not at all) to 10 (Extreme increased pain). Q1. During your treatment, did you experience increased pain or stiffness at the treated area? Q2. During your treatment, did you experience increased pain or stiffness in another treatment-related area? Adverse events from the psychological intervention (MoodGYM) were monitored by an enquiry at the weekly telephone reminder calls. As part of ethics approval, participants who reported psychological distress from using MoodGYM, were offered the opportunity to contact an experienced clinical psychologist to discuss any issues of psychological distress that may have arisen throughout the entirety of the study. This would be recorded as an adverse event from the psychological intervention.

\section{Sample size calculations}

A total of 108 participants were required to show a statistically significant between-group difference for the primary outcomes (disability and self-efficacy) with a moderate Glass's delta effect size of 0.60 standard deviations (SD), with a power of $80 \%$ (alpha $=0.05$ ) and with a potential $15 \%$ drop-out rate. This sample size was also adequate to detect a between-group difference of $>9$ points in PSEQ score [44], and a between-group difference of $>4$ points in the RMD $[44,45]$.

\section{Statistical methods}

As this was an exploratory and not a confirmatory trial, we did not use any statistical methods to control for testing multiple outcomes, as recommended by Bender and Lange (2001) [46]. This approach avoided the generation of type II errors [47]. We considered it important to include information of the multiple outcomes measured for descriptive purposes and did not intend them 
to be used for definitive proof in decision making. Thus, primary and secondary analyses were conducted using the same method of linear mixed models. The effect size was computed as Glass's delta, that is the mean between group difference/SD of the control group.

Analysis was performed using intention-to-treat. At analysis, all participants were maintained in the group to which they were allocated regardless of non-attendance, withdrawal, or loss to follow-up. The primary analyses used linear mixed models to test for between group differences in PSEQ and RMD at post-treatment (week 8), 6- months and 12- months follow-up. As linear mixed models were used to analyse the data all participants were included in each analysis regardless of any missing data points. This process avoided the need to impute missing data which could have the effect of falsely increasing the power of the study and thus precision in the estimates, and of biasing results towards the null hypothesis. Two tailed significance values of $p<.05$ were considered to indicate statistical significance in betweengroups differences. Statistical assumptions were satisfied for this analysis, that is, there were no influential outliers, the residuals were normally distributed, and an appropriate covariance structure was used.

\section{Results \\ Participants}

Figure 1 details the participant flow through the trial. In total, 361 volunteers were screened for eligibility, of which 253 did not fulfill the inclusion criteria: 168 (66.5\%) were classified as at either high-risk or low-risk of ongoing disability according to the STarT Back tool; $80(31.6 \%)$ did not meet other inclusion criteria. Of these 28 had an active workers compensation claim, 12 had recent spinal surgery, 6 were pregnant, 8 had a diagnosed malignancy, 11 had spinal nerve compromise and 15 were unable to independently complete questionnaires in English language. Additionally, 5 volunteers subsequently

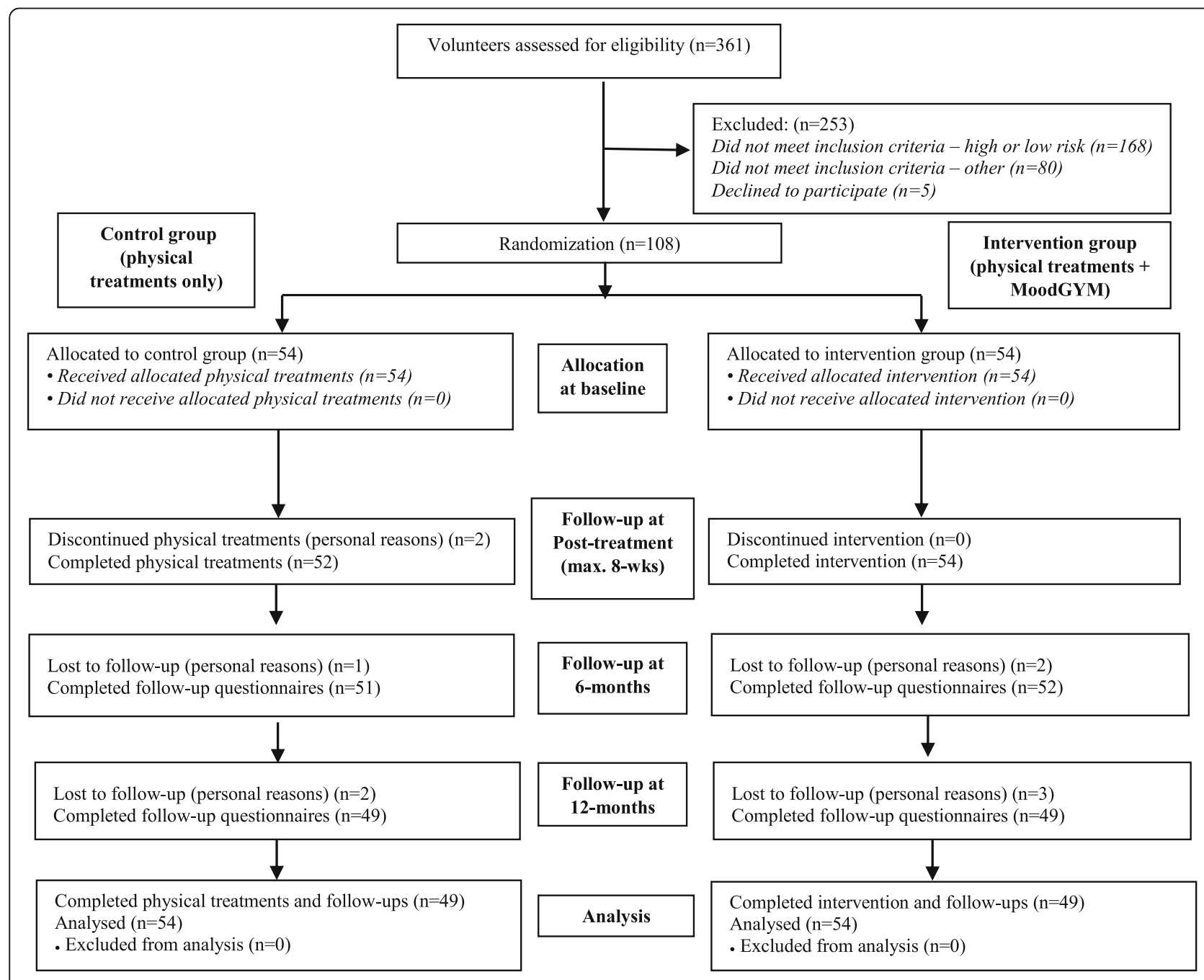

Fig. 1 Flow of Participants 
declined to participate. In total, 108 participants were enrolled. At baseline, there were no significant participant characteristic differences between the two groups (Table 2). In line with the CONSORT statement, we did not statistically test for differences in baseline characteristics. Any differences between the characteristics would have been due to chance and not bias, and baseline testing would merely verify the efficiency of the randomisation process. While it is acknowledged that some authors undertake baseline testing, a systematic evaluation by Peterson et al. [48] argues the practice should be discouraged. Characteristics related to study outcomes were not observed to be largely different between the groups.

Participants were middle aged, slightly above normal weight, had moderate levels of back pain, low level of disability, high level of self-efficacy and normal-mild levels of psychological distress.

Employment and health status of participants are also presented in Table 2. Approximately, two-thirds of participants had constant back pain for more than five years. In total, $40 \%$ were in full-time employment and approximately half stated that the number of hours worked each week was affected by pain. Furthermore, $62 \%$ stated that their type of employment was governed by their experience and expectations of back pain. Fortyfour percent did not attribute a specific cause to their back pain. The two most common comorbidities by participants were depression and anxiety (24.1\%) and osteoarthritis (18.5\%).

\section{Primary and secondary outcomes}

Participants in the control group received mean 7.7 (SD 2.0) physical treatments and those in the intervention group received mean 7.7 (SD 2.4). There was no statistically significant difference between the two groups in either disability $(p=.70)$ or self-efficacy $(p=.52)$ at any follow-up time points. (Table 3). Between group effect sizes were small to very small and are presented in Table 4. A statistically significant within-group reduction in disability was observed for both groups at post-treatment $(p<.001)$ which was maintained at 6 and 12 months. It is not clear whether this change was due to treatment or nontreatment effects such as a regression to the mean. The changes in primary outcomes over time within-groups can be visualised in Fig. $2 a$ and $b$.

\section{Adverse events}

No severe or serious adverse events of physical treatment were reported (Table 5). No adverse events were reported by participants using MoodGYM. Some participants reported short-term mild (25.9\%) or moderate (8.3\%) pain associated with physical treatment. No participants discontinued treatment due to adverse events.

\section{Treatment adherence}

Each participant in the intervention group completed all five MoodGYM modules, confirmed verbally by participants at weekly telephone calls. If a participant stated that they had not started or completed a module by the time of their weekly phone call, they were asked to complete the module within two days. A follow-up phone call was made to ensure that the module had been completed. The participants was instructed to continue with the next module and a weekly telephone call was made the following week.

\section{Discussion}

This study found that a combination of physical treatments and access to the MoodGYM program was not more effective than physical treatments alone for improving disability and self-efficacy in people with chronic non-specific LBP at medium risk of ongoing disability. These results align with previous research which found no clinically significant differences between physical, behavioural/psychologically informed, and combined interventions in those treated for non-specific LBP [49]. That is, a combined treatment was not better than physical treatment alone.

There are several possible explanations why no difference in outcomes between the two treatment groups were found in the present study.

First, selecting participants at the high-risk of ongoing disability may have been a more appropriate target for the current trial. As suggested by Ailliet et al. (2016), psychosocial factors have minimal added value in predicting outcomes in patients presenting to chiropractors with non-specific LBP unless they are in the high-risk group [50]. Furthermore, improvements previously identified in a study of CBT for chronic back pain are predominately related to people with low levels of selfefficacy, high levels of disability and high levels of depression or anxiety, as they generally respond better to CBT [51].

Second, patient self-efficacy of our sample was already relatively high at baseline (mean 44.5, SD 12.3) compared to normative values for people with LBP (mean 25.5, SD 13.4) [33]. Thus, a ceiling effect may have existed at baseline leaving little room for further improvement among participants exposed to the combined intervention. Furthermore, MoodGYM was designed to improve depressive symptoms in non-clinical populations $[2,13,19,52]$. As self-efficacy is a known mediator in the relationship between chronic pain and depression [53], further research should examine how chiropractic and physiotherapy and interventions can better target self-efficacy with back pain treatments. Furthermore, participants in this study had normal-mild levels of psychological distress and thus may not have been optimal 
Table 2 Participant characteristics at baseline by Group (values are mean \pm SD for continuous variables and N (\%) for dichotomous variables)

\begin{tabular}{|c|c|c|c|}
\hline & Control group $(n=54)$ & Intervention group $(n=54)$ & Total $(n=108)$ \\
\hline \multicolumn{4}{|l|}{ Participants } \\
\hline Age (years) & $50.6(14.4)$ & $50.1(12.8)$ & $50.4(13.6)$ \\
\hline Male & $22(40.7 \%)$ & $32(46.3 \%)$ & $54(50 \%)$ \\
\hline Female & $25(59.3 \%)$ & $29(53.7 \%)$ & $54(50 \%)$ \\
\hline BMl & $26.7(4.0)$ & $27(5.0)$ & $26.8(4.5)$ \\
\hline \multicolumn{4}{|l|}{ Pain Intensity } \\
\hline PNRS (0-10) & $4.9(2.0)$ & $5.1(1.8)$ & $5.0(1.9)$ \\
\hline \multicolumn{4}{|l|}{ Pain Duration } \\
\hline $3-12$ months & $3(5.6 \%)$ & $1(1.9 \%)$ & $6(5.5 \%)$ \\
\hline 12 months -2 years & $6(11.1 \%)$ & $8(14.8 \%)$ & $14(13.0 \%)$ \\
\hline $2-5$ years & $8(14.8 \%)$ & $8(14.8 \%)$ & $16(14.8 \%)$ \\
\hline$>5$ years & $37(68.5 \%)$ & $35(64.8 \%)$ & $72(66.7 \%)$ \\
\hline \multicolumn{4}{|l|}{ Pain Description } \\
\hline Always present, level of pain varies & $32(59.3 \%)$ & $36(66.7 \%)$ & $68(63.0 \%)$ \\
\hline Often present, with pain-free periods $<6 \mathrm{~h}$ & $14(25.9 \%)$ & $10(18.5 \%)$ & $24(22.2 \%)$ \\
\hline \multicolumn{4}{|l|}{ Cause of Pain } \\
\hline Injury at home & $3(5.6 \%)$ & $5(9.3 \%)$ & $8(7.4 \%)$ \\
\hline Injury at work & $8(14.8 \%)$ & $8(14.8 \%)$ & $16(14.8)$ \\
\hline Motor vehicle accident & $4(7.4 \%)$ & $2(3.7 \%)$ & $6(5.6 \%)$ \\
\hline No obvious cause & $25(46.3 \%)$ & $23(42.6 \%)$ & $48(44.4 \%)$ \\
\hline Injury other setting & $6(11.1 \%)$ & $7(13.0 \%)$ & $13(12.0 \%)$ \\
\hline \multicolumn{4}{|l|}{ Functional Status } \\
\hline RMD (0-24) & $9.9(4.7)$ & $9.9(4.2)$ & $9.9(4.4)$ \\
\hline PSFS (0-10) & $4.1(1.3)$ & $4.2(1.5)$ & $4.2(1.4)$ \\
\hline WAI (0-10) & $5.6(2.1)$ & $5.7(2.1)$ & $5.7(2.1)$ \\
\hline \multicolumn{4}{|l|}{ Psychological Status } \\
\hline PSEQ (0-60) & $37.8(13.0)$ & $40.1(10.0)$ & $44.5(12.3)$ \\
\hline PCS Total (0-52) & $20.9(12.5)$ & $20.0(11.3)$ & $20.5(11.9)$ \\
\hline PCS Rumination (0-16) & $7.59(4.3)$ & $7.6(4.2)$ & $7.6(4.2)$ \\
\hline PCS Magnifying (0-12) & $4.2(3.0)$ & $3.6(2.8)$ & $3.9(2.9)$ \\
\hline PCS Helplessness (0-24) & $9.1(6.0)$ & $8.9(5.6)$ & $9.0(5.8)$ \\
\hline DASS21 Total (0-63) & $16.8(12.6)$ & $15.0(10.1)$ & $15.9(11.4)$ \\
\hline DASS21 Depression (0-21) & $5.5(5.3)$ & $5.3(4.8)$ & $5.4(5.0)$ \\
\hline DASS21 Anxiety (0-21) & $3.6(3.6)$ & $2.8(2.9)$ & $3.2(3.3)$ \\
\hline DASS21 Stress (0-21) & $7.7(4.7)$ & $7.0(3.9)$ & $7.3(4.3)$ \\
\hline \multicolumn{4}{|l|}{ Work Status } \\
\hline Full-time & $21(38.9 \%)$ & $24(44.4 \%)$ & $45(41.7 \%)$ \\
\hline Part-time & $14(25.9 \%)$ & $18(33.3 \%)$ & $32(29.6 \%)$ \\
\hline Work hours affected by pain & $26(48.1 \%)$ & $23(42.6 \%)$ & $49(45.4 \%)$ \\
\hline Work type affected by pain & $34(63 \%)$ & $33(61.1 \%)$ & $67(62.0 \%)$ \\
\hline \multicolumn{4}{|l|}{ Health Status } \\
\hline Self-reported depression/ anxiety & $14(25.9 \%)$ & $12(22.2 \%)$ & $26(24.1 \%)$ \\
\hline Osteoarthritis & $12(22.2 \%)$ & $8(14.8 \%)$ & $20(18.5 \%)$ \\
\hline
\end{tabular}


Table 2 Participant characteristics at baseline by Group (values are mean \pm SD for continuous variables and N (\%) for dichotomous variables) (Continued)

\begin{tabular}{llll}
\hline & Control group $(n=54)$ & Intervention group $(n=54)$ & Total $(n=108)$ \\
\hline High blood pressure & $10(18.5 \%)$ & $4(7.4 \%)$ & $14(13.0 \%)$ \\
Stomach ulcer & $2(3.7 \%)$ & $4(7.4 \%)$ & $6(5.6 \%)$ \\
\hline
\end{tabular}

Note: $B M I$ (body mass index), PNRS (pain numeric rating scale, RMD (roland morris disability questionnaire), PSFS (patient specific functional scale), WAI (work ability index), PSEQ (patient self-efficacy questionnaire), PCS (pain catastrophizing scale), DASS21 (depression anxiety stress 21-item scale)

candidates to benefit from this intervention tool. The normative data in the literature for the DASS-21 are as follows: Scores for the depression scale for 'Normal' are 0-4, 'Mild' are 5-6, 'Moderate' are 7-10, 'Severe' are 11-13 and 'Extremely Severe' are 14+. Scores for the anxiety scale for 'Normal' are $0-3$, 'Mild' are 4-5, 'Moderate' are 6-7, 'Severe' are 8-9 and 'Extremely Severe' are 10+. Scores for the stress scale for 'Normal' are 0-7, 'Mild' are 8-9, 'Moderate' are 10-12, 'Severe' are 13-16 and 'Extremely Severe' are 17+ [38]. At baseline, the mean score for depression in both the control and intervention groups for the was 5.4, which is within the 'Mild' range. The mean score for anxiety in both the control and intervention groups was 3.1, which is within the 'Normal' range. The mean score for stress in both the control and intervention groups was 7.3, which is also within the 'Mild' range.
Third, the MoodGYM program content may not have been specific enough for people with back pain. This study is the first trial to use MoodGYM in a back pain population. When MoodGYM was used in populations with a specific diagnosis such as Multiple Sclerosis (MS), it was found that participants did not relate to the resources within the modules because it was not specific to them [22]. It is possible that a modification to MoodGYM that includes back pain case examples and resources, may be more meaningful to patients in boosting self-efficacy and improving their funactional disability .

Fourth, it is possible that adherence to MoodGYM was not optimal. Unfortunately, we were not able to ascertain objective data on participants adherence to the program, although participants reported compliance on the weekly telephone reminder calls with the research assistant. Poor adherence has been observed in previous

Table 3 Mean (SD) and p-value for between group differences using linear mixed models

\begin{tabular}{|c|c|c|c|c|c|c|c|c|c|}
\hline \multirow[b]{3}{*}{ Outcome } & \multirow{2}{*}{\multicolumn{2}{|c|}{$\begin{array}{l}\text { Baseline } \\
\text { Mean (SD) }\end{array}$}} & \multirow{2}{*}{\multicolumn{2}{|c|}{$\begin{array}{l}\text { Post-treatment } \\
\text { (max. 8-weeks) } \\
\text { Mean (SD) }\end{array}$}} & \multirow{2}{*}{\multicolumn{2}{|c|}{$\begin{array}{l}6 \text { months } \\
\text { Mean (SD) }\end{array}$}} & \multirow{2}{*}{\multicolumn{2}{|c|}{$\begin{array}{l}12 \text { months } \\
\text { Mean (SD) }\end{array}$}} & \multirow{3}{*}{$\begin{array}{l}\text { Mean differences } \\
\text { between groups } \\
\text { (0-12 months) } \\
p \text { value }\end{array}$} \\
\hline & & & & & & & & & \\
\hline & $\begin{array}{l}\text { Control } \\
\text { group } \\
(n=54)\end{array}$ & $\begin{array}{l}\text { Intervention } \\
\text { group } \\
(n=54)\end{array}$ & $\begin{array}{l}\text { Control } \\
\text { group } \\
(n=54)\end{array}$ & $\begin{array}{l}\text { Intervention } \\
\text { group } \\
(n=52)\end{array}$ & $\begin{array}{l}\text { Control } \\
\text { group } \\
(n=52)\end{array}$ & $\begin{array}{l}\text { Group } 2 \\
\text { Intervention } \\
(n=51)\end{array}$ & $\begin{array}{l}\text { Control } \\
\text { group } \\
(n=49)\end{array}$ & $\begin{array}{l}\text { Intervention } \\
\text { group } \\
(n=49)\end{array}$ & \\
\hline \multicolumn{10}{|l|}{ Primary } \\
\hline RMD & $9.9(4.7)$ & $9.9(4.2)$ & $5.8(5.1)$ & $5.4(3.8)$ & $5.0(4.6)$ & $5.1(4.0)$ & $5.3(5.1)$ & $4.2(3.7)$ & 0.70 \\
\hline PSEQ & $37.8(13.0)$ & $40.1(10.0)$ & $44.3(13.8)$ & $45.2(12.0)$ & $45.7(11.5)$ & $45.9(11.7)$ & $47.6(12.2)$ & $50.2(9.4)$ & 0.52 \\
\hline \multicolumn{10}{|l|}{ Secondary } \\
\hline \multicolumn{10}{|l|}{ Pain and function } \\
\hline PNRS & $4.9(2.05)$ & $5.1(1.8)$ & $2.9(2.0)$ & $2.8(2.0)$ & $3.2(2.2)$ & $3.2(2.2)$ & $4.0(2.1)$ & $3.0(2.1)$ & 0.95 \\
\hline WAI & $5.6(2.1)$ & $5.7(2.1)$ & $6.3(2.3)$ & $6.5(2.0)$ & $6.4(2.3)$ & $6.5(1.9)$ & $6.2(2.5)$ & $6.8(2.2)$ & 0.62 \\
\hline \multicolumn{10}{|l|}{ Psychological } \\
\hline PCS Total & $20.9(12.5)$ & $20.0(11.3)$ & $14.9(10.5)$ & $15.5(11.6)$ & $11.5(8.8)$ & $13.4(9.8)$ & $12.8(10.1)$ & $11.8(10.0)$ & 0.89 \\
\hline PCS Rumination & $7.6(4.3)$ & $7.6(4.2)$ & $5.8(4.1)$ & $5.6(4.1)$ & $4.6(3.7)$ & $5.1(3.7)$ & $5.1(4.2)$ & $4.5(3.7)$ & 0.97 \\
\hline PCS Magnification & $4.2(3.0)$ & $3.6(2.8)$ & $2.8(2.2)$ & $2.9(2.6)$ & $2.1(1.8)$ & $2.4(2.2)$ & $2.6(2.2)$ & $2.1(2.5)$ & 0.69 \\
\hline PCS Helplessness & $9.1(6.0)$ & $8.9(5.6)$ & $6.4(4.9)$ & $7.0(5.7)$ & $4.8(3.9)$ & $6.0(4.6)$ & $5.1(4.4)$ & $5.2(4.8)$ & 0.61 \\
\hline DASS21 Total & $16.8(12.6)$ & $15.0(10.1)$ & $13.3(11.3)$ & $12.2(9.5)$ & $11.0(9.0)$ & $10.8(7.3)$ & $11.2(9.4)$ & $9.8(8.1)$ & 0.49 \\
\hline DASS21 Depression & $5.5(5.3)$ & $5.3(4.8)$ & $4.2(4.5)$ & $4.2(4.6)$ & $3.0(3.0)$ & $3.7(3.8)$ & $3.5(3.5)$ & $3.2(3.5)$ & 0.98 \\
\hline DASS21 Anxiety & $3.6(3.6)$ & $2.8(2.9)$ & $3.0(3.3)$ & $2.4(2.7)$ & $2.6(3.0)$ & $2.0(2.1)$ & $2.7(3.3)$ & $2.1(2.5)$ & 0.19 \\
\hline DASS21 Stress & $7.7(4.7)$ & $7.0(3.9)$ & $6.1(4.3)$ & $5.6(3.3)$ & $5.4(3.8)$ & $5.2(3.1)$ & $5.0(3.7)$ & $4.4(3.2)$ & 0.41 \\
\hline
\end{tabular}

Note: The baseline within-group means were calculated from baseline data. The within-group mean estimates for post-treatment 6 and 12 - months were calculated from linear mixed models 
Table 4 Between-group effect sizes at post-treatment, 6 - months and 12 - months

\begin{tabular}{|c|c|c|c|c|c|c|}
\hline \multirow[b]{2}{*}{ Primary Outcomes } & \multicolumn{2}{|l|}{ Post-treatment } & \multicolumn{2}{|l|}{6 - month } & \multicolumn{2}{|l|}{12 - month } \\
\hline & Effect Size $(95 \% \mathrm{Cl})$ & $\overline{\text { Magnitude }}$ & Effect Size $(95 \% \mathrm{Cl})$ & $\overline{\text { Magnitude }}$ & Effect Size (95\%Cl) & $\overline{\text { Magnitude }}$ \\
\hline RMD & $-0.06(-0.45,0.31)$ & very small & $0.01(-0.38,0.39)$ & very small & $-0.20(-0.62,0.17)$ & small \\
\hline PSEQ & $0.06(-0.31,0.45)$ & very small & $0.02(-0.36,0.41)$ & Very small & $0.21(-0.16,0.63)$ & small \\
\hline
\end{tabular}

Effect Size very small $<0.20$, small 0.20 , medium 0.50 , large 0.80
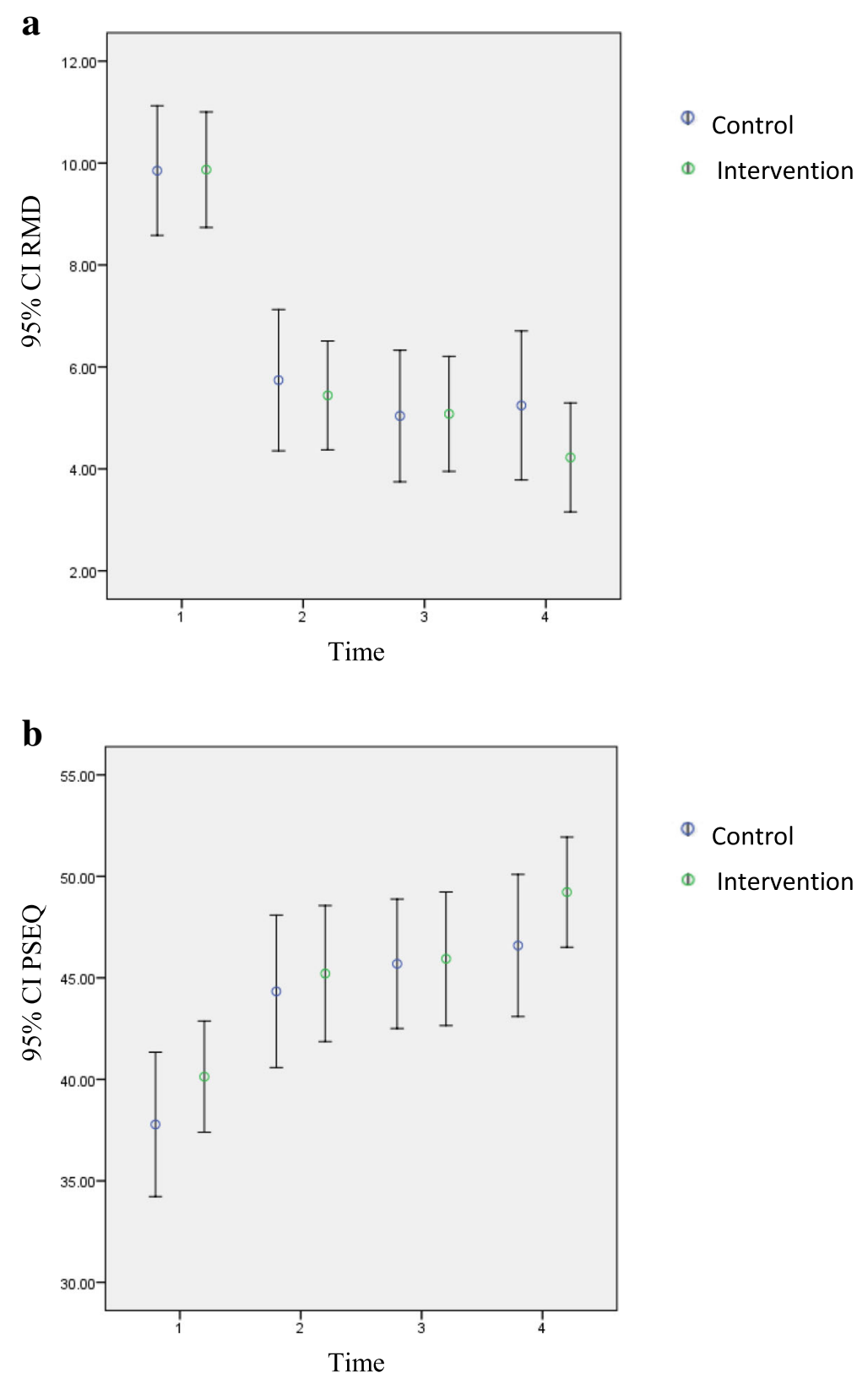

NB: $1=$ baseline, $2=$ post-treatment, $3=6-$ months and $4=12-$ months

Fig. 2 a Changes in RMD primary outcomes over time within-groups. b Changes in PSEQ primary outcomes over time within-groups 
Table 5 Adverse events to physical treatments

\begin{tabular}{lll}
\hline & Pain at treated area & Pain non-treated area \\
& $\%$ & $\%$ \\
\hline $1-2$ not at all & 63.9 & 72.2 \\
$3-5$ mild & 25.9 & 21.3 \\
6 moderate & 8.3 & 4.6 \\
$7-10$ severe & 0.0 & 0.0 \\
\hline
\end{tabular}

studies using MoodGYM and other internet-delivered CBT programs with adherence levels below 10\% [54], and has been noted as a large contributor to poor results for depression outcomes [19, 54-57].

\section{Strengths and limitations}

A strength of this study lies in trialing a biopsychosocial approach in manual therapy practice using a validated, no-cost, readily accessible secondary prevention tool (MoodGYM).

In addition to the discussion points above, there are several major limitations of this trial. The first being the application of MoodGYM to individuals at medium-risk of ongoing disability (individuals with low to no psychological risk factors) [58], as this program was designed specifically for managing depression and anxiety in a non-clinical group, not for improving self-efficacy in an LBP population. Moreover, the trial population had normal-mild levels of psychological distress at baseline. However, at the time of planning this trial, MoodGYM was the most appropriate intervention that had the potential of acting as a secondary prevention psychosocial tool, it had met evidence standards for efficacy and effectiveness criteria set by the Society for Prevention Research (SPR) [23], and had substantially met the standards of evidence for public dissemination [24].

Furthermore, there remains some uncertainty about the use of the SBST in people with chronic low back pain. The tool is reported to perform well for disability in medium risk, however, there remains uncertainty of its overall predictive ability in chronic back pain populations [59].

Further limitations of the study included recruitment methods. Recruitment methods used in the trial may have included two different population groups. That is, participants that responded to media editorials and advertisements may be distinctly different to those directly seeking care at the chiropractic, physiotherapy and GP clinics. Research suggests that people seek care for back pain based on high pain and disability levels, and fear that pain would impact work or life [60]. As the majority of people with chronic LBP do not seek care directly (55.5\%) [60] it is possible that those responding to the editorials may have been coping with their pain better than those seeking care, and may have had higher levels of self-efficacy and believed their back pain would not affect their work or life. If recruitment was only offered to those seeking care the level of self-efficacy among participants may have been low at baseline. Participants seeking additional care outside of the trial was permitted in this pragmatic study, however data was not tracked and its potential impact on outcomes was not measured which is acknowledged as a potential limitation of the study findings.

Further research may involve a process evaluation to assess participants experiences of the trial that may inform the development of a back pain specific internetdelivered secondary prevention tool. Furthermore, secondary analysis of data may reveal important psychosocial predictors of treatment outcome which would further inform in-the-field practitioners that treat patients at medium-risk.

Although this study reported negative results, we believe that this trial was important because; (1) it contributes to biopsychosocial research that addresses the secondary prevention of psychological distress in a chronic LBP population; (2) it has tested a wellresearched internet-based CBT program content of which could potentially be modified to better assist the chronic LBP population by addressing physical and psychosocial factors.

\section{Conclusions}

There was no additional benefit of an internet-delivered CBT program (MoodGYM) to physical treatments in those with chronic non-specific LBP at medium risk of ongoing disability measured at post-treatment, or at 6 and 12 months. Future trials should investigate the effect of an internet-delivered CBT program in those at highrisk of ongoing disability.

\section{Acknowledgements \\ We would like to thank Kylie Bennett from e-hub Health (formerly from The Australian National University Centre for Mental Health Research) for provid- ing her insights on the use and development of MoodGYM. A special ac- knowledgement to Dr. Jennifer Peat biostatistician at The University of Sydney for her assistance and review of statistical methods.}

\section{Authors' contributions}

All named authors made substantial contributions to the conception and design of the trial; MJP, MM were primarily responsible for ethics approval and trial registration. Treatment centre recruitment was conducted by MJP, MM and AL. Participant recruitment was primarily conducted my MJP. All coauthors contributed to the analysis and interpretation of data. All co-authors contributed to the revision of drafted manuscript and approved the submitted version for submission. All authors read and approved the final manuscript.

\section{Funding}

This research did not receive any specific grant from funding agencies in the public, commercial, or not-for-profit sectors.

Availability of data and materials

The datasets generated and/or analysed during the current study are not publicly available, as secondary analysis is currently being undertaken with 
the intention of being published but are available from the corresponding author on reasonable request.

\section{Ethics approval and consent to participate}

The trial was approved by The University of Sydney Human Research Ethics Committee (protocol number 2014/997). Recruitment commenced on March 30, 2015 and ended June 2017.

\section{Consent for publication}

Written informed consent was obtained from all participants prior to entering the trial for publication of their anonymous and non-identifiable details in this manuscript. The consent forms are held securely by the University of Sydney Research Data Store in accordance with ethics approved protocol and is available for review by the Editor-in-Chief.

\section{Competing interests}

There are no conflicts of interest to declare for any of the authors or those mentioned in the acknowledgements.

\section{Author details}

${ }^{1}$ Discipline of Physiotherapy, Faculty of Health Sciences, The University of Sydney, Sydney, Australia. ${ }^{2}$ Department of Health Sciences, Vrije Universiteit, Amsterdam, The Netherlands. ${ }^{3}$ Discipline of Behavioural and Social Sciences in Health, Faculty of Health Sciences, The University of Sydney, Sydney, Australia.

\section{Received: 3 April 2019 Accepted: 16 August 2019}

Published online: 25 October 2019

\section{References}

1. Baird A, Sheffield D. The relationship between pain beliefs and physical and mental health outcome measures in chronic low Back pain: direct and indirect effects. Healthcare. 2016:4:58

2. Kamper SJ, Apeldoorn AT, Chiarotto A, Smeets RJ, Ostelo RW, Guzman J, van Tulder MW. Multidisciplinary biopsychosocial rehabilitation for chronic low back pain: Cochrane systematic review and meta-analysis. BMJ. 2015; 350:h444.

3. Maher CUM, Buchbinder R. Non-specific low back pain. Lancet. 2016;6736: $1 \mathrm{e} 12$.

4. Hayden JA, van Tulder MW, Tomlinson G. Systematic review: strategies for using exercise therapy to improve outcomes in chronic low back pain. Ann Intern Med. 2005;142:776-85.

5. Ferreira ML, Ferreira PH, Latimer J, Herbert RD, Hodges PW, Jennings MD, Maher CG, Refshauge KM. Comparison of general exercise, motor control exercise and spinal manipulative therapy for chronic low back pain: a randomized trial. Pain. 2007:131:31-7.

6. Nicholas MK, Wilson PH, Goyen J. Comparison of cognitive-behavioral group treatment and an alternative non-psychological treatment for chronic low back pain. Pain. 1992:48:339-47.

7. Picha KJ, Jochimsen KN, Heebner NR, Abt JP, Usher EL, Capilouto G, Uhl TL. Measurements of self-efficacy in musculoskeletal rehabilitation: a systematic review. Musculoskeletal care. 2018.

8. Airaksinen O, Brox JI, Cedraschi C, Hildebrandt J, Klaber-Moffett J, Kovacs F, Mannion AF, Reis S, Staal JB, Ursin H, et al. European guidelines for the management of chronic nonspecific low back pain. Eur Spine J. 2006; 15(Suppl 2):S192-300.

9. Low back pain in adults: early management. NICE guidelines [CG88] [http:// www.nice.org.uk/guidance/cg88].

10. Qaseem A, Wilt TJ, McLean RM, Forciea M, for the clinical guidelines Committee of the American College of P. Noninvasive treatments for acute, subacute, and chronic low back pain: a clinical practice guideline from the american college of physicians. Ann Intern Med. 2017.

11. Rubinstein SM, van Middelkoop M, Assendelft WJ, de Boer MR, van Tulder MW. Spinal manipulative therapy for chronic low-back pain: an update of a Cochrane review. Spine (Phila Pa 1976). 2011;36:E825-46.

12. Bernstein IA, Malik Q, Carville S, Ward S. Low back pain and sciatica: summary of NICE guidance. BMJ. 2017;356.

13. Hill JC, Fritz JM. Psychosocial influences on low back pain, disability, and response to treatment. Phys Ther. 2011;91:712-21.

14. Bandura A. Self-efficacy: toward a unifying theory of behavioral change. Psychol Rev. 1977:84:191-215.
15. Sztein DM, Koransky CE, Fegan L, Himelhoch S: Efficacy of cognitive behavioural therapy delivered over the Internet for depressive symptoms: A systematic review and meta-analysis. J Telemed Telecare 2017: $1357633 \times 17717402$

16. Nicholas Henschke, Raymond WJG Ostelo, Maurits W van Tulder, Johan WS Vlaeyen, Stephen Morley, Willem JJ Assendelft, Chris J. Main: Behavioural treatment for chronic low-back pain. The Cochrane Collaboration. Published by John Wiley \& Sons, Ltd.; 2010.

17. Lamb SE, Lall R, Hansen Z, Castelnuovo E, Withers EJ, Nichols V, Griffiths F, Potter R, Szczepura A, Underwood M. Be STtg: A multicentred randomised controlled trial of a primary care-based cognitive behavioural programme for low back pain. The Back Skills Training (BeST) trial. Health Technol Assess. 2010;14:1-253 iii-iv.

18. Buhrman M, Gordh T, Andersson G. Internet interventions for chronic pain including headache: a systematic review. Internet Interv. 2016:4:17-34

19. Twomey C, O'Reilly G. Effectiveness of a freely available computerised cognitive behavioural therapy programme (MoodGYM) for depression: meta-analysis. Aust N Z J Psychiatry. 2017;51:260-9.

20. O'Kearney R, Gibson M, Christensen H, Griffiths KM. Effects of a cognitivebehavioural internet program on depression, vulnerability to depression and stigma in adolescent males: a school-based controlled trial. Cogn Behav Ther. 2006;35:43-54

21. Topolovec-Vranic J, Cullen N, Michalak A, Ouchterlony D, Bhalerao S, Masanic C, Cusimano MD. Evaluation of an online cognitive behavioural therapy program by patients with traumatic brain injury and depression. Brain Inj. 2010;24:762-72.

22. Hind D, O'Cathain A, Cooper CL, Parry GD, Isaac CL, Rose A, Martin L, Sharrack B. The acceptability of computerised cognitive behavioural therapy for the treatment of depression in people with chronic physical disease: a qualitative study of people with multiple sclerosis. Psychol Health. 2010;25: 699-712.

23. Flay BR, Biglan A, Boruch RF, Castro FG, Gottfredson D, Kellam S, Mościcki EK, Schinke S, Valentine JC, Ji P. Standards of evidence: criteria for efficacy, effectiveness and dissemination. Prev Sci. 2005:6:151-75.

24. Christensen $H$, Griffiths $K$. Reaching standards for dissemination: a case study. Stud Health Technol Inform. 2007;129:459-63.

25. Haldane D: MoodGYM: http://moodgym.anu.edu.au. Occup Med 2006, 56: 586-586.

26. Moher D, Hopewell S, Schulz KF, Montori V, Gøtzsche PC, Devereaux P, Elbourne D, Egger M, Altman DG. CONSORT 2010 explanation and elaboration: updated guidelines for reporting parallel group randomised trials. Bmj. 2010;340:c869.

27. Petrozzi MJ, Leaver A, Jones MK, Ferreira PH, Rubinstein SM, Mackey MG Does an online psychological intervention improve self-efficacy and disability in people also receiving multimodal manual therapy for chronic low back pain compared to multimodal manual therapy alone? Design of a randomized controlled trial. Chiropr Man Ther. 2015;23:1.

28. Hill JC, Whitehurst DGT, Lewis M, Bryan S, Dunn KM, Foster NE, Konstantinou K, Main CJ, Mason E, Somerville S, et al. Comparison of stratified primary care management for low Back pain with current best practice (STarT Back): a randomised controlled trial. Lancet. 2011;378:156071.

29. Walker BF, French SD, Grant W, Green S. A Cochrane review of combined chiropractic interventions for low-back pain. Spine. 2011;36:230-42.

30. [ehub Health https://moodgym.com.au/ (last accessed 25 July 2019)].

31. Tuomi K. IJ, Jahkola A, Katajarinnie L, Tulkki A: Work Ability Index. Helsinki: Finnish Institute of Occupational Health; 1991

32. Nicholas MK. The pain self-efficacy questionnaire: taking pain into account Eur J Pain. 2007;11:153-63.

33. Nicholas MK, Asghari A, Blyth FM. What do the numbers mean? Normative data in chronic pain measures. Pain. 2008;134:158-73.

34. Roland M, Morris R. A study of the natural history of back pain: part I: development of a reliable and sensitive measure of disability in low-back pain. Spine. 1983;8:141-4.

35. Sullivan MJ, Bishop SR, Pivik J. The pain catastrophizing scale: development and validation. Psychol Assess. 1995;7:524-32.

36. Sullivan MJ: The Pain Catastrophizing Scale User Manual pp. 1-36: Departments of Psychology, Medicine, and Neurology School of Physical and Occupational Therapy McGill University Montreal, Quebec; 2009 1-36.

37. Stratford P. Assessing disability and change on individual patients: a report of a patient specific measure. Physiother Can. 1995;47:258-63. 
38. Lovibond SH, Lovibond PF. Manual for the depression anxiety stress scales. 2nd ed. Sydney: Psychology Foundation; 1995.

39. Jensen MP, Karoly P. Self-reported scales and procedures for assessing pain in adults. In: Turk DC, Melzack R, editors. Handbook of pain assessment. New York: Guilford Press; 1992. p. 193-213.

40. Ioannidis JP, Evans SJ, Gøtzsche PC, O'neill RT, Altman DG, Schulz K, Moher D. Better reporting of harms in randomized trials: an extension of the CONSORT statement. Ann Intern Med. 2004;141:781-8.

41. Organization WH. World alliance for patient safety: WHO draft guidelines for adverse event reporting and learning systems: from information to action. Geneva: World Health Organization; 2005.

42. Carnes D, Mullinger B, Underwood M. Defining adverse events in manual therapies: a modified Delphi consensus study. Man Ther. 2010;15:2-6.

43. Rubinstein SM, Leboeuf-Yde C, Knol DL, de Koekkoek TE, Pfeifle CE, van Tulder MW. The benefits outweigh the risks for patients undergoing chiropractic care for neck pain: a prospective, multicenter, cohort study. J Manip Physiol Ther. 2007;30:408-18.

44. Maughan EF, Lewis JS. Outcome measures in chronic low back pain. Eur Spine J. 2010;19:1484-94.

45. Jordan K, Dunn KM, Lewis M, Croft P. A minimal clinically important difference was derived for the Roland-Morris disability questionnaire for low back pain. J Clin Epidemiol. 2006:59:45-52.

46. Bender R, Lange S. Adjusting for multiple testing —-when and how? J Clin Epidemiol. 2001;54:343-9.

47. Perneger TV. What's wrong with Bonferroni adjustments. Bmj. 1998;316: $1236-8$

48. Peterson RL, Tran M, Koffel J, Stovitz SD. Statistical testing of baseline differences in sports medicine RCTs: a systematic evaluation. BMJ Open Sport Exerc Med. 2017;3:e000228.

49. O'Keeffe M, Purtill H, Kennedy N, Conneely M, Hurley J, O'Sullivan P, Dankaerts W, O'Sullivan K: Comparative effectiveness of conservative interventions for nonspecific chronic spinal pain: physical, behavioral/ psychologically informed, or combined? A systematic review and metaanalysis. J Pain 2016:Epub ahead of print 2016.

50. Ailliet L, Rubinstein SM, Hoekstra T, van Tulder MW, de Vet HC. Adding psychosocial factors does not improve predictive models for people with spinal pain enough to warrant extensive screening for them at baseline. Phys Ther. 2016;96:1179-89.

51. Rasmussen-Barr E, Campello M, Arvidsson I, Nilsson-Wikmar L, Ang BO. Factors predicting clinical outcome 12 and 36 months after an exercise intervention for recurrent low-back pain. Disabil Rehabil. 2012;34:136-44

52. Currie SR, Wang J. More data on major depression as an antecedent risk factor for first onset of chronic back pain. Psychol Med. 2005;35:1275-82.

53. Arnstein P, Caudill M, Mandle CL, Norris A, Beasley R. Self efficacy as a mediator of the relationship between pain intensity, disability and depression in chronic pain patients. Pain. 1999:80:483-91.

54. Lillevoll KR, HCB V, Griffiths KM, Waterloo K, Eisemann MR. Uptake and adherence of a self-directed internet-based mental health intervention with tailored e-mail reminders in senior high schools in Norway. BMC Psychiatry. 2014:14:14 ArtID 142014

55. Neil AL, Batterham P, Christensen H, Bennett K, Griffiths KM. Predictors of adherence by adolescents to a cognitive behavior therapy website in school and community-based settings. J Med Internet Res. 2009;11:42-9.

56. Calear AL, Christensen H, Mackinnon A, Griffiths KM. Adherence to the MoodGYM program: outcomes and predictors for an adolescent schoolbased population. J Affect Disord. 2013;147:338-44.

57. Batterham PJ, Neil AL, Bennett K, Griffiths KM, Christensen H. Predictors of adherence among community users of a cognitive behavior therapy website. Pat Preference Adherence. 2008;2:97.

58. Hill JC, Dunn KM, Lewis M, Mullis R, Main CJ, Foster NE, Hay EM. A primary care back pain screening tool: identifying patient subgroups for initial treatment. Arthritis Care Res. 2008;59:632-41.

59. Kendell M, Beales D, O'Sullivan P, Rabey M, Hill J, Smith A. The predictive ability of the STarT Back tool was limited in people with chronic low back pain: a prospective cohort study. J Phys. 2018;64:107-13.

60. Walker BF, Muller R, Grant WD. Low back pain in Australian adults. Health provider utilization and care seeking. J Manip Physiol Ther. 2004;27:327-35.

\section{Publisher's Note}

Springer Nature remains neutral with regard to jurisdictional claims in published maps and institutional affiliations.

Ready to submit your research? Choose BMC and benefit from:

- fast, convenient online submission

- thorough peer review by experienced researchers in your field

- rapid publication on acceptance

- support for research data, including large and complex data types

- gold Open Access which fosters wider collaboration and increased citations

- maximum visibility for your research: over $100 \mathrm{M}$ website views per year

At BMC, research is always in progress.

Learn more biomedcentral.com/submissions 